\title{
Recognizing the Italian zones most prone to next large earthquakes: possible approaches and present chances
}

\author{
Enzo Mantovani, Dario Albarello, Caterina Tamburelli and Daniele Babbucci \\ Dipartimento di Scienze della Terra, Università di Siena, Italy
}

\begin{abstract}
The defense from earthquakes in Italy would be considerably favoured by knowing where the next strong shocks will most probably occur. However, to obtain this information a well-defined and widely accepted method is not yet available. This work discusses the approaches so far proposed and tries to estimate the relative chances of providing reliable indications on this problem. Particular attention focusses on the methodology based on the concept of «strain migration».
\end{abstract}

Key words seismic hazard - time dependence Italian zone

\section{Introduction}

From the known seismic history of Italy it is plausible to expect that in the next few tens of years (a reasonable time span for economic planning) this region may be hit by a few (1-2) strong earthquakes. To know in advance where these events will occur would considerably simplify and make more efficient the planning of prevention initiatives of Civil Protection (like, for instance, the reinforcement of old buildings). Unfortunately, obtaining this kind of information is no easy task. A number of statistical, empirical and deterministic methodologies have been so far proposed in the world to try to estimate the time pattern of seismic

Mailing address: Prof. Enzo Mantovani, Dipartimento di Scienze della Terra, Settore di Geofisica, Università di Siena, Via Banchi di Sotto 55, 53100 Siena, Italy; e-mail: mantovani@unisi.it hazard, but the reliability of the results obtained cannot be easily assessed, often due to the limited time intervals available for checking the proposed predictions.

In this work an attempt is made to understand which one of the proposed approaches has the highest chances of giving interesting results in the Central Mediterranean tectonic context.

\section{Statistical methods}

This kind of approach is based on the statistical analysis of seismic catalogues, through which one tries to obtain significant information on the behaviour of seismic activity in a given zone. This information, usually represented by the statistical distribution which is presumed to satisfactorily fit the data set, is then used to estimate the probability of occurrence of future earthquakes in the near future in the zone considered within a given time.

This methodology was recently applied to the Italian region by Boschi et al. (1995), who tentatively identified the most probable sites of 
larger crustal earthquakes in the next 5, 20 and 100 years. As underlined by the above authors, the estimate of the reliability of the results obtained by this kind of approach is not easy since there are several possible sources of uncertainty whose effective contribution is poorly known. For instance, the analysis of seismicity data for hazard estimates requires a division of the Italian territory in zones, which is necessarily made in a subjective way, even if plausible seismotectonic considerations are taken into account. This choice involves an intrinsic difficulty: the larger the zones considered the greater the probability of having a numerous data set with a consequent mitigation of the uncertainty on hazard estimates. However, it is not clear what the practical usefulness may be of knowing the average hazard level in a large zone, where the distribution of seismic activity may be significantly heterogeneous. This problem obviously decreases when smaller zones, more coherent with the dimensions of real active structures, are taken into account, but in this case the number of events within each zone is more limited and consequently the uncertainty of the computed parameters, such as the average return times, may considerably increase.

The approach of Boschi et al. (1995) was based on the regionalization of Italy proposed by the «Gruppo Nazionale per la Difesa dai Terremoti» of the Italian Research Council (Scandone, 1992). This choice involves a relatively low number of events in the zones considered (from 1 to 9, with an average of roughly 3 ). This is probably due to the long return periods of strong earthquakes in the Italian seismogenetic structures, as also suggested by paleoseismological studies (e.g., Pantosti et al., 1993). Given the paucity of the above data sets, one could believe that reliable estimates of return time probability distribution may hardly be obtained.

An interesting example of this problem is provided by the results obtained by Boschi et al. (1995) concerning the Abruzzi Apennines zone, i.e., one of the two zones recognized as most prone to intense earthquakes in the near future (5 years). The «seismic behaviour» of this zone for events with $M \geq 5.9$ has been de- rived from a data set constituted by three earthquakes spaced by two very similar interevent times $(61 \pm 2$ years). This led to estimate a very high short-term hazard for this zone, where no $M \geq 5.9$ shocks have occurred for the last 200 years. In this case, a delay of roughly 140 years with respect to the expected time of occurrence of the «next» event suggests a very low confidence on the reliability of the return times obtained for this zone.

The problems of probabilistic methods mentioned above are also underlined by the fact several cases have been reported of recent large earthquakes in the world which occurred in zones classified as poorly dangerous (e.g., Wakefield and Pendick, 1995; Stiros, 1995; Pavlides et al., 1995).

\section{Empirical and deterministic methods}

\subsection{Independent and «regular» seismic sources}

This kind of approach is based on the assumption that no significant interaction exists between different sources and that the behaviour of seismogenetic zones presents some regularities, connected with the homogeneity over time of some source parameters. The most popular examples of this approach are the «time» and «slip predictable» and the «characteristic earthquake» models (e.g., Bufe et al., 1977; Shimazaki and Nakata, 1980; Sykes and Quittmeyer, 1981; Schwartz and Coppersmith, 1984; Nishenko, 1985; Papazachos, 1989).

The «time predictable» model assumes the static stress as constant on the fault. This feature, if associated to a uniform accumulation rate, implies the possibility to predict the time interval which will separate the last event, characterized by a given stress drop, from the subsequent one.

The «slip predictable» model assumes instead a constant dynamic stress on the fault. This condition would allow to predict the amount of seismic slip (and then the presumed magnitude) of the expected event, on the basis of the time elapsed from the last shock (still assuming a uniform accumulation rate). 
A widely accepted definition of the «characteristic earthquake» model is not yet available. In general, this concept implies that most of the seismic moment on a fault is released in repeats of earthquakes of essentially the same size. However, it is not yet clear if the prediction must be only confined to the magnitude of the next shock, as suggested by the original definition of Schwartz and Coppersmith (1984), or whether it may also involve other parameters, like the return time (see Kagan and Jackson, 1995, for a recent discussion about this problem).

This kind of approach has been mainly applied to zones of the world where seismic activity is associated with large tectonic structures, like for instance the S. Andreas fault system in California (Bufe et al., 1977; Sykes and Quittmeyer, 1981; Anagnos and Kiremidjan, 1984; Nishenko, 1985; Papazachos, 1989), but no clear evidence is so far available on the applicability of this methodology to seismic zones characterized by wide and complex fracturation, like the Italian region. Recent checks on the capability of these simplified models to represent the real seismic behaviour in some zones of the World (Kagan and Jackson, 1995) and in the Italian area (Mulargia and Gasperini, 1995) have mainly provided negative indications.

In our opinion, the major problem in applying this approach to Italy is that the underlying assumptions about the uniformity over time of the static and/or dynamic stresses and of the accumulation rate can hardly be fulfilled. The Apenninic-Maghrebian belt, where most of the Italian seismicity is located, has experienced very intense deformations, with considerable reorganizations of masses, in the last millions of years and thus it is reasonable to believe that its structures are characterized by widespread fracturation. In this context, the probability that the dimensions and/or the geometry and/or the slip of seismic faults in a given zone may remain constant from one shock to the next does not appear to be very high, due to the possible variations of «internal» features, like the total frictional forces along the fault, and «external» conditions, like the regional stress field, in response to seismic activations in the surrounding zones during the seismic cycle.

\subsection{Seismic gap}

Various definitions of «seismic gap» have been reported in the relevant literature since the initial proposal of Fedotov (1965). Originally this concept was interpreted as a consequence of the «seismic cycle» hypothesis, in the sense that «earthquake hazard» is small immediately following a large shock and increases with time from the last strong event on certain active fault segments or plate boundaries. This version of the model was used for long-term forecasting by Sykes (1971) in the Alaska-Aleutian area and by Kelleher et al. (1973) and McCann et al. (1979) in the whole Pacific rim. The forecasts of Kelleher et al. (1973) and McCann et al. (1979) were statistically tested by Kagan and Jackson (1991) who pointed out a scarce success of these predictions in the ensuing decade. These negative results were confirmed by further analysis by Richardson et al. (1993), Nishenko and Sykes (1993) and Kagan and Jackson (1994).

An attempt to use the old «seismic gap» concept to infer earthquake potential in the Mediterranean area was made by Purcaru and Berckhemer (1982), who identified two major gaps in the Iblean and Marmara seismic zones. However, no strong earthquakes have so far occurred in the above zones.

To overcome these problems, Nishenko and Sykes (1993) proposed a new version of the seismic gap model which, in addition to the time elapsed since the last large event, takes into account the size distribution of strong events and their recurrence times, expressing the earthquake potential in a quantitative way, as the probability of earthquake occurrence in certain time-space magnitude windows. This model assumes that large earthquakes on a particular fault segment follow the characteristic earthquake distribution (Schwartz and Coppersmith, 1984; Davison and Scholz, 1985). This «new seismic gap» model has been applied by Nishenko (1991) to the circum-Pacific rim to 
estimate earthquake potentials for the next 5 , 10 and 20 years. These predictions, referring to the first 5 year period, were tested by Kagan and Jackson (1995) who found that this method tends to predict too many characteristic earthquakes with respect to the real seismic sequences.

In our opinion, the definition of «seismic gap» which seems to be most plausible from the physical point of view is that based on the existence of a well known large seismic structure composed of a number of separated but tectonically connected segments. Only in this case does it appear plausible to suppose that the delay of seismic release in a given segment, after most other sectors have been affected by strong events within relatively short time intervals, may imply a high seismic hazard in the presumed «gap zone» in the near future. Interesting examples of this kind of behaviour were reported by Anderson (1975) for circum-Pacific seismic belts.

However, the condition mentioned above would imply that the «seismic gap» method may only be applied in a few regions of the world, where large scale well known seismic belts exist and that its application to regions characterized by complex and largely unknown fracturation like the Italian region, may hardly provide reliable predictions.

The first application of this concept to the Italian region was made at the beginning of this century by Omori (1909), who identified the Apenninic belt as a continuous active belt constituted by a number of segments. On the basis of the available seismic history he recognized two possible seismic gaps: the central and Southernmost Apennines. One of these gaps was soon filled by the strong Avezzano earthquake (1915), but the other prediction still awaits confirmation. In the latter area, the Pollino zone, paleoseismological studies suggest the occurrence of Olocene seismic activity, but further investigations on historical records did not provide any evidence of seismic disasters (Valensise and Guidoboni, 1995).

In our opinion, the hypothesis of Omori (1909), in spite of its initial success in predicting the Avezzano earthquake, may hardly be used as a basis for the application of the seismic gap concept in the Italian region. The idea that the seismic belt running from the Northern Apennines to the Calabrian arc may be interpreted as a unique, even if segmented, seismogenetic structure, activated by a coherent tectonic mechanism is not supported by the analysis of the Neogenic-Quaternary deformation pattern of this zone (Mantovani et al., 1996, $1997 \mathrm{a}, \mathrm{b})$. This analysis rather suggests that the tectonic mechanisms responsible for seismic activity in the various sectors of the belt, like the Northern Central and Southern Apennines, the Calabrian arc and Sicily, are different, even though they are all consequences of the convergence between the Africa/Arabia system and Eurasia and the kinematics of the Adriatic plate (Mantovani et al., 1997a). In other words, we believe that there are no precise tectonic justifications for expecting that the delay of seismic release in a given segment of the Apenninic-Maghrebian belt, after the occurrence of strong earthquakes in the other sectors, implies a high value of seismic hazard in the near future. On the other hand, this kind of interpretation does not find any systematic support from the analysis of the time-space distribution of major earthquakes in the Italian area.

Some considerations can be made, in particular, for the Pollino zone, i.e. the potential seismic gap recognized by Omori (1909), which has attracted great attention during recent years, inducing paleoseismological and historical investigations. This zone lies just at the corner between the Calabrian arc, a seismotectonic structure moving roughly SEward, and the Southern Apennines, moving almost coherently with the Adriatic plate (Mantovani et al. 1997a,b and references therein). Well differentiated kinematic and tectonic behaviours of these two sectors, allowed by transversal decoupling zones, were also proposed by other authors (e.g., Finetti and Del Ben, 1986; Rehault et al., 1987; Patacca et al., 1990). In this context, it seems difficult to identify a common tectonic mechanism possibly underlying the concept of gap in the Pollino zone. Is it connected with the motion of Calabria? or with that of the Southern Apennines? or with the relative motion between these two sectors? 
The idea that the apparently aseismic sectors in the elongated seismic belt along the Italian peninsula and Calabrian arc should be filled soon or later might be reasonable, but this hypothesis can hardly help to predict whether the next seismic activation of the Pollino zone is close or far in time.

\subsection{Pattern recognition}

This kind of approach is based on the assumption that the phase preceding strong earthquakes is characterized by a significant alteration of some parameters connected with seismicity rate and space-time distribution of minor events (e.g., Keilis-Borok and Kosobokov, 1986). A major problem of this methodology is the high number of choices it requires for the definition of the several parameters involved and the scarce possibility to check the significance and reliability of the values finally adopted. A statistical check of the results provided by this methodology in the Southwestern Pacific zone (Habermann and Creamer, 1994) pointed out that the observed variations of seismicity parameters are in fact related to changes in the system for detecting and reporting earthquakes rather than to actual changes in physical processes occurring in the Earth.

This approach (method M8) has been used to recognize the «Times of Increased Probability (TIP)» of earthquake occurrence in the Italian region (Keilis-Borok et al., 1990; Costa et al., 1995, 1996). The results obtained are not encouraging, because of the high percentage of false alarms (generally greater than $50 \%$ ) and of the relatively large extent of the zones involved. Furthermore, plausible answers to a number of questions on the physical mechanism underlying this method have still to be found. For instance, it is not easy to understand why an alteration of seismicity parameters in Central or Southern Italy should precede the occurrence of a strong shock in Northern Italy, as tentatively assumed by Costa et al. (1995).

Understanding the underlying mechanism is not strictly required, this being an empirical approach, but it would certainly increase confidence in its chances of success. For instance, it seems reasonable to think that the probability of obtaining good results should increase as the dimension of the zone considered becomes smaller and smaller, up to possibly reaching an overlap between the domain of precursors and that of events to be predicted.

\subsection{Multidisciplinary approaches}

In order to mitigate the uncertainties associated with the methodologies described above, a number of authors proposed the use of approaches which blend information from geology, paleoseismology, space geodesy, observational seismology and synthetic seismicity (e.g., WGCEP (Working Group on California Earthquake Prediction), 1995; Ward, 1994). Geology and paleoseismology may help in 1ocating and estimating the long-term slip velocity of principal faults. Geodetic measurements are used to obtain some constraints on strain accumulation rates, especially in the zones where no other information is available (e.g., blind faults). Observational seismology is used to connect rates of geodetic strains with rates of seismic moment release. Then, synthetic seismicity is used to understand possible statistical distribution of events in regions of wide and multiple faulting.

So far, this kind of approach has mainly been applied to California, i.e., a region for which the estimate of seismic hazard presents quite different problems with respect to Italy, both concerning the tectonic setting and the length of seismic catalogues. Thus the applicability of this method to Italy can hardly be estimated. The direct measure of strain accumulation rates by geodetic observations may undoubtedly constitute an important privileged piece of information with respect to other approaches. However, it must be considered that an accurate monitoring of this parameter all over the Italian seismic zones would require considerable effort, in terms of long (several years) observational campaigns. Furthermore, even assuming that a reliable estimate of strain accumulation rates can be finally obtained, it 
remains to be seen how to use this information to recognize the possible sites of the next large earthquakes. To this purpose, it is necessary to make hypotheses on how the accumulated strain will be released, for instance by one or a few large shocks or by several intermediateminor events, and on the location of the eventual large earthquakes.

\subsection{Interdependent sources}

This kind of approach is based on the hypothesis that strain/stress accumulation rates in a given seismic zone and thus the probability of earthquakes may be significantly altered by the occurrence of strong earthquakes in the surrounding tectonically connected regions. This hypothesis might explain seismicity regularity patterns observed in some regions of the world (e.g., Dewey, 1976; Mogi, 1985; Mantovani and Albarello, 1997) and direct observations of strain migration (Kasahara, 1979). Available evidence suggests migration velocities from some tens to some hundreds of $\mathrm{km} / \mathrm{yr}$. Theoretical works (e.g., Bott and Dean, 1973; Anderson, 1975; Albarello and Bonafede, 1990) have shown that a stressed elastic lithospheric plate riding on a viscous or viscoelastic layer may be used to quantitatively interpret the major features of the observed migration patterns.

This phenomenon seems to be the most likely one responsible for the regular migration of earthquakes in the North Anatolian Fault System (NAFS) which followed the large triggering shock of 1939 in the easternmost sector of this fault (e.g., Dewey, 1976). If, for instance, large earthquakes occur again in the easternmost sector of the NAFS, it seems plausible to believe that seismic hazard in the adjacent sectors of the same discontinuity would undergo a significant increase. Stein et al. (1997), by computing the changes of Coulomb failure stress induced by some events of the 1939 sequence on the adjacent sectors of the same fault, demonstrated that the seismicity migration along the North Anatolian fault was most probably influenced by the interaction between seismic sources.
The observational evidence and the theoretical computations mentioned above strongly support the plausibility of the phenomenon underlying this kind of approach. However, the applicability of this method to other zones, such as Italy, where no large well defined fault systems are recognized, has yet to be demonstrated. For example, the computation of the changes of failure stress in the NAFS after the 1939 event was favoured by the fact that in that case the tectonic mechanism underlying stress transfer and the geometry of the potential seismic sources to be activated are known fairly well (Barka, 1992). This suggests that the chances of estimating the accelerations of strain/stress accumulation rates in the Italian seismic sources, induced by significant releases of seismic energy in the surrounding zones, are strongly dependent on the level of knowledge of the present tectonic mechanisms in the Central Mediterranean region and of the geometries of the major potential seismic sources in Italy.

In this regard, we think that during the last few years the reconstruction of the recent geodynamic evolution and of the present tectonic setting of the Central Mediterranean region has undergone a considerable improvement, due to an efficient exploitation of the huge amount of geological, petrological and geophysical information which has allowed simple and coherent explanations for the time-space distribution of Neogene-Quaternary deformation events (see Mantovani et al., 1997a and references therein) and for the present day seismotectonic evidence (Mantovani et al., 1997b). In the next section, we synthetically describe the major aspects of the proposed geodynamic interpretation and we argue that its seismotectonic implications might help to recognize the periods of highest seismic hazard in some Italian seismic zones.

\section{Proposed deterministic approach}

\subsection{Present tectonic setting}

Figure 1 shows the main tectonic features in the Central Mediterranean area. It is possible to note that the Italian region mostly lies on the western border of the Adriatic plate, a Meso- 


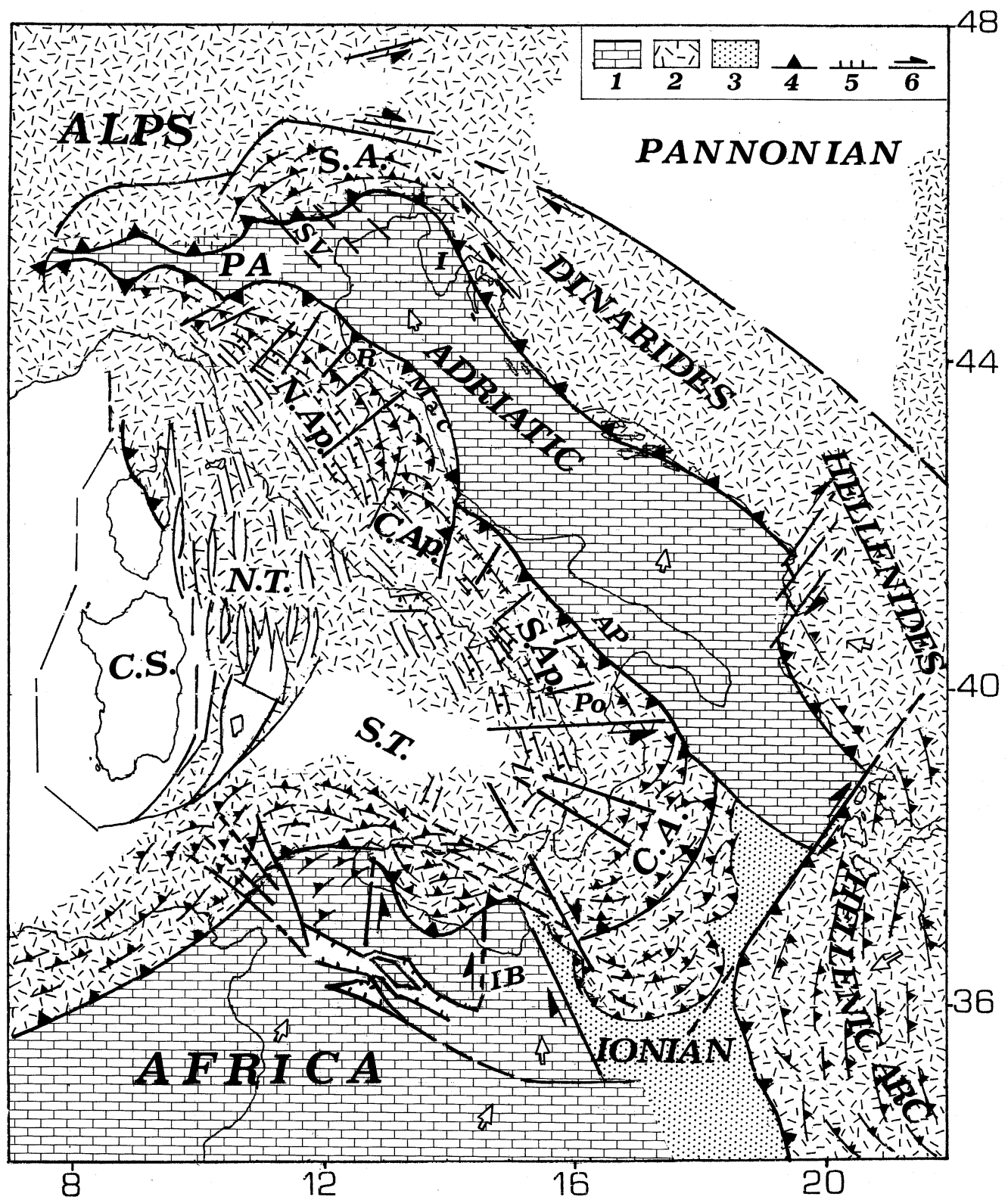

Fig. 1. Tectonic/kinematic sketch of the Central Mediterranean region. 1) Africa/Adriatic domain; 2) main orogenic belts; 3) thinned African margin (Ionian); 4,5,6) main compressional, tensional and transcurrent features. $\mathrm{AP}=$ Apulian swell; C.A. = Calabrian arc; C.Ap. = Central Apennines; C.S. = Corsica-Sardinia massif; $\mathrm{I}=$ Istrian zone; IB = Iblean plateau; Mac = Marche coast; N.Ap. = Northern Apennines; N.T. = Northern Tyrrhenian; PA = Padanian zone; Po = Pollino zone; $\mathrm{R}=$ Rimini area; S.A. = Southern Alps; S.Ap. $=$ Southern Apennines; S.T. $=$ Southern Tyrrhenian; S.V. = Schio-Vicenza line. Empty arrows indicate the movements of major blocks with respect to Eurasia. 
zoic platform which seems to be still characterized by a coherent kinematic behaviour from the Southern Alps to the Ionian zone (e.g., Mantovani et al., 1997a, b). The present shape of this plate derives from a complex timespace distribution of consuming processes which considerably reduced its original extension and caused a strong bilateral flexure of its southern part, with the consequent formation of the Apulian structural high (see, e.g., Royden et al., 1987; Kruse and Royden, 1994; Mantovani et al., 1997a,b). Uparching in the Southern Adriatic mainly developed during the upper Pliocene, just before the end of the consuming process in the Southern Apennines. During this phase, in fact, the strong squeezing that the Adriatic plate was undergoing in between the Aegean-Balkan system, moving roughly westward, and Africa, moving roughly NEward, was scarcely accommodated by the consumption of its margins since the AdriaticBalkan border was inactive and the Adriatic Southern Apennines border was gradually becoming inactive. Thus, during this period the convergence of the surrounding blocks was mainly accommodated by flexuring, with consequent uparching, of the Southern Adriatic platform. This deformation pattern underwent a drastic change around the late Pliocene-early Pleistocene, when the underthrusting of the Adriatic plate beneath the Southern DinaridesHellenides reactivated, accompanied by the gradual unbending of the Adriatic platform (Kruse and Royden, 1994).

At present, the Central Mediterranean zone is stressed by the westward motion of the Anatolian-Aegean-Balkan system and by the NE to NNE motion of Africa with respect to Eurasia (fig. 1). These kinematic boundary conditions are accommodated by a complex pattern of shortening processes, as suggested by geological and geophysical evidence (see Mantovani et al., 1997a,b and references therein):

a) The underthrusting of the Northern Adriatic plate beneath the Southern Alps (e.g., Slejko et al., 1989; Roure et al., 1996). The lateral decoupling between the northern part of the Adriatic block, moving roughly NNW to $\mathrm{NW}$, and the adjacent Padanian-Apennines and Dinaric zones are accommodated by transpres- sional fault systems (e.g., Castellarin and Vai, 1986; Royden, 1988; Slejko et al., 1989).

b) The underthrusting of the Southern Adriatic plate beneath the Southern Dinarides-Hellenides (e.g., Biju-Duval et al., 1977; Mercier et al., 1989; Anderson and Jackson, 1987).

c) Lateral escapes of crustal wedges and uplift in the Calabrian arc and Apennines. The convergence between Africa and the Adriatic plate is accommodated by the roughly northward escape of the Iblean wedge, the eastward escape of Calabria and by the oroclinal bending (through outward displacements and relative block rotations) of the Apenninic belt (fig. 1). This last phenomenon is particularly evident in the sectors of the belt, like the Northern Apennines, which are facing the Central-Northern Adriatic foreland zones where the flexural bulge, located in the Istrian zone (e.g., Royden et al., 1987), is still relatively far from the external front of the chain and thus the consumption of the Adriatic lithosphere does not encounter great resistance (Mantovani et al., 1997a).

In the Southern Apennines, instead, any further outward displacement of the belt is inhibited by the Apulian swell (see, e.g., Patacca et al., 1990) and thus this sector of the chain moves almost coherently with the adjacent Adriatic plate (fig. 1).

\subsection{Seismotectonic implications}

From the kinematic-tectonic setting described above (fig. 1) and from mechanicalrheological considerations (e.g., Anderson, 1975), one could expect that each seismic activation of peri-Adriatic decoupling zones, presumably associated to dislocations at the related borders, may have some influence on strain accumulation in the other periAdriatic potential seismogenetic structures.

\section{Northern Adriatic}

When significant seismic slip occurs at the Northern Adriatic border (fig. 2) in the Southern Alps, one could expect that stresses and 


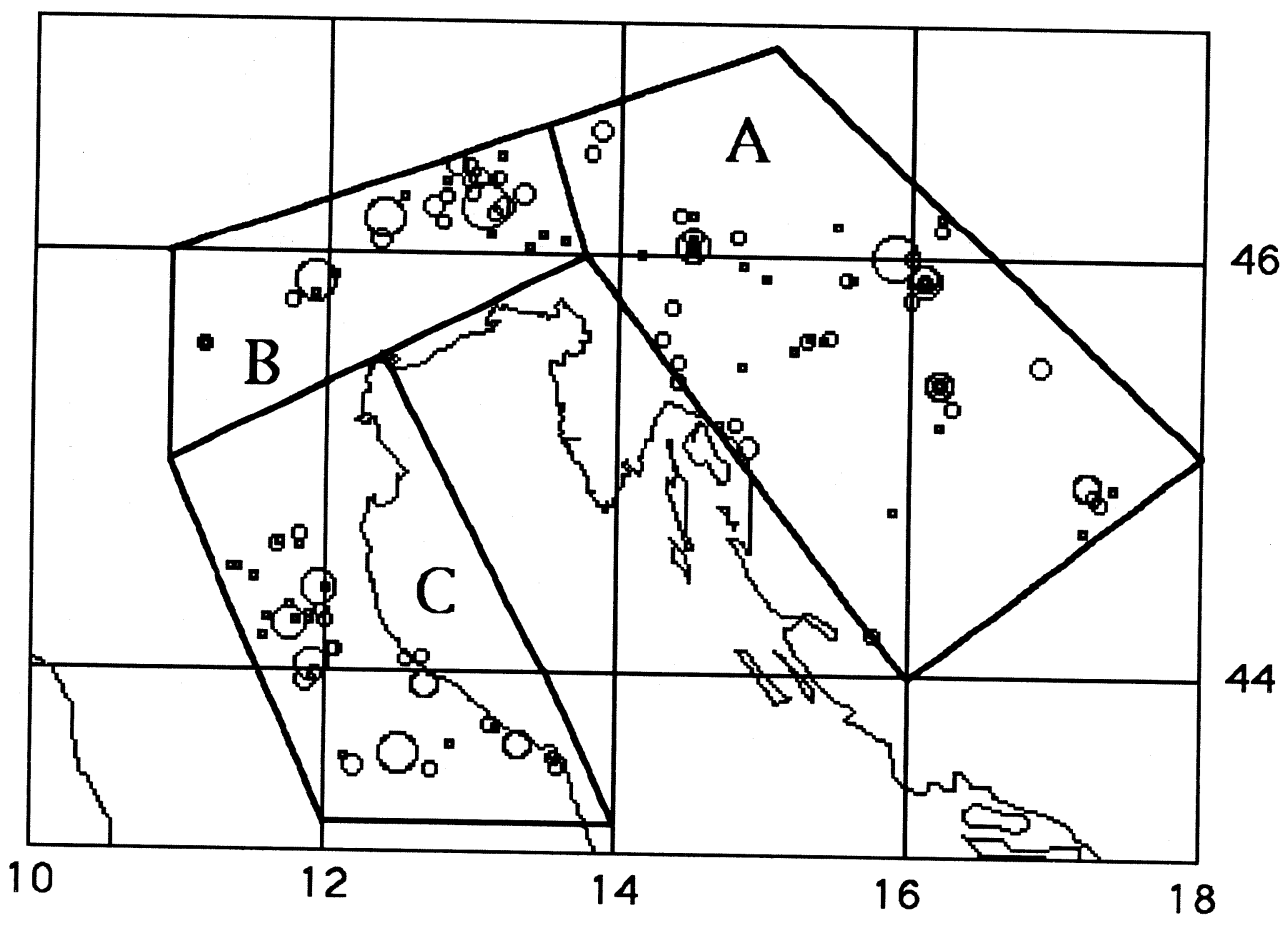

Fig. 2. Seismotectonic regions representing the lateral decoupling shear zones $(\mathrm{A}, \mathrm{C})$ and the northern compressional border (B) of the Adriatic plate. Epicenters of events with $M \geq 5$ for the period 1650-1980 are reported in the figure. Data from Shebalin et al. (1974) and Ribarich (1982) for the Dinaric zone and from Camassi and Stucchi (1996) for the Italian zones. A) Northern Dinarides. This zone is characterized by systems of mainly SE-NW strike-slip faults which decouple the main Adriatic body from the Pannonian-Carpathian ern Apennines-Po Valley. Along this border the main Adriatic plate underthrusts the Alpine edifice. C) Northtween the main Adriatic tween the main Adriatic body and the Northern Apennines-Padanian system (see Mantovani et al., 1997b).

strains increase along the lateral transcurrent guides of the Adriatic plate (in the PadanianNorthern Apennines zone on one side, and in the Northern Dinarides, on the other side), with a consequent rise of the probability of earthquake occurrence in those zones. This consideration also holds in the opposite sense: when strong shocks occur along the lateral Apenninic and Dinaric decoupling zones, stresses and strains are expected to increase at the Northern Adriatic border.

In a purely elastic situation, the perturbation triggered by large events will flow at elastic wave speeds and the other decoupling zones of the Northern Adriatic plate will know within seconds or minutes that they must support an increase in stress. In an elastic layer overlying a ductile layer, which seems to be the probable structural setting in the Adriatic plate (Viti et al., 1997), part of the strain perturbation travels more slowly, compatibly with the relaxation time of the viscous layer.

The above seismotectonic interpretation might help to explain some features of the seismicity time patterns (fig. 3) in the zones (fig. 2) implied in the proposed tectonic mechanism. In particular, the fact that seismic activity in all zones is mostly concentrated in relatively short periods of 10-20 years (see fig. 3), separated by relatively long periods of low 


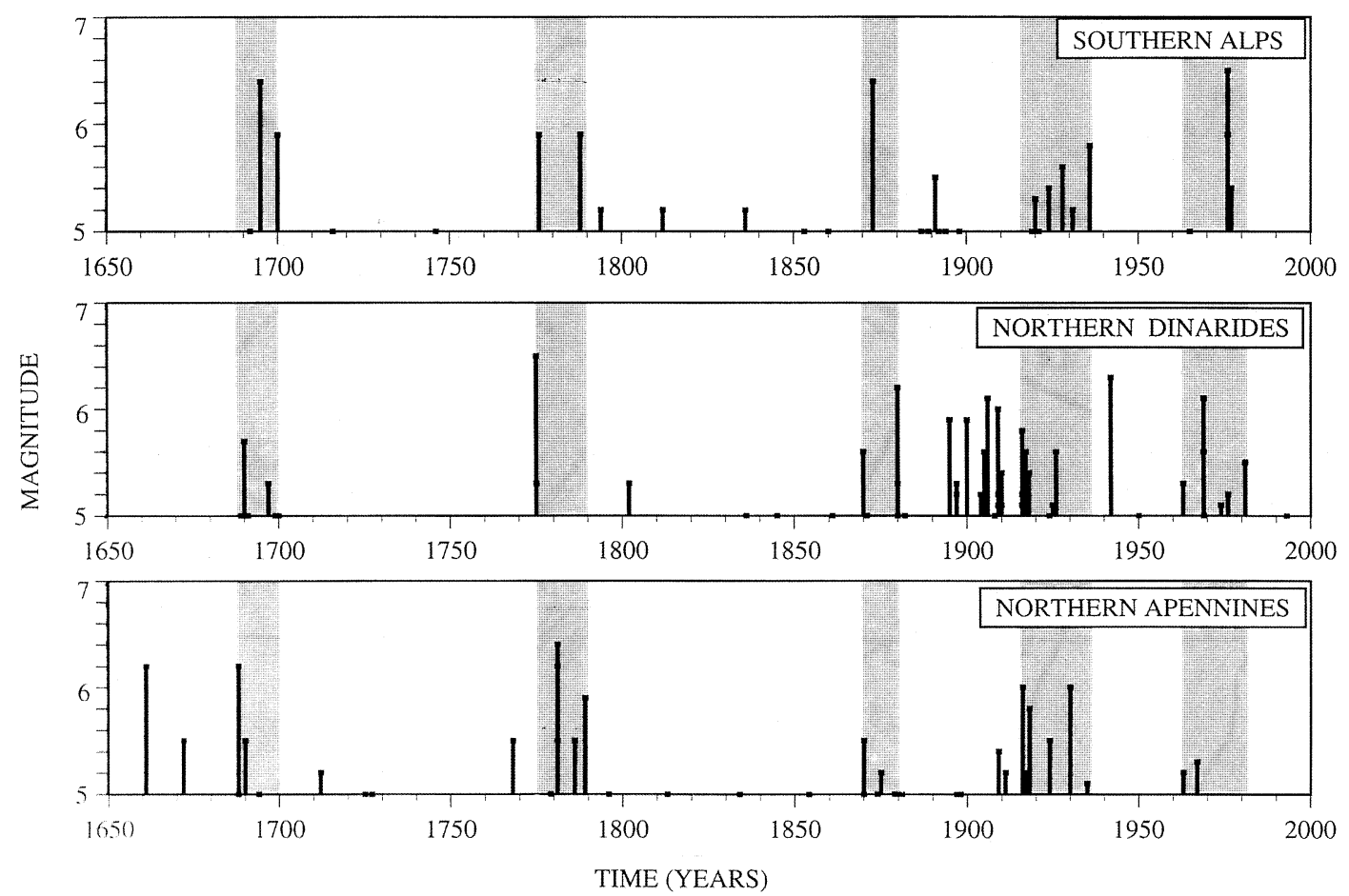

Fig. 3. Seismicity patterns in the last three centuries in the zones shown in fig. 2. It is possible to note that most seismic activity in the three zones considered is concentrated in short time intervals (evidenced by shaded bands), separated by long periods of relative quiescence. Further comments in the text.

seismicity or quiescence. Outside the periods mentioned above intense earthquakes are rare, the only exception concerns the active period in the Northern Dinarides around 1900. This distribution suggests a discontinuous character of seismicity in the zones considered and the tendency of the active periods in the various zones to overlap or to occur within a few years one from the other. It might be interesting to note that the major seismic activations of the Southern Alps have been almost regularly preceded by a number of earthquakes with $M>5$ in the Northern Apennines and Northern Dinarides. In the last active period, around 1970, the activity in the Northern Apennines appears to be lower than in the previous seismic crises; however, it must be pointed out that in 1972 a long series of events, with magnitudes com- prised between 3.5 and 5 , occurred in the seismic belt running just off the Marche coast. This case could indicate that the activation of the above decoupling shear zone (whose possible tectonic significance is discussed by Mantovani et al., 1997b) is not necessarily marked by intense earthquakes.

\section{Southern Adriatic}

As extensively argued by Mantovani et al. (1997a,b), Southern Italy and the Adriatic plate are squeezed in between Africa and the Aegean-Balkan system (fig. 1). These boundary conditions are accommodated by uplift in the whole collision zone, from Sicily to the Southern Apennines through the Calabrian arc, 
and by the underthrusting of the Eastern Adriatic margin beneath the Hellenides-Dinarides belt. The latter phenomenon, in our opinion, is mainly responsible for the seismic activity in Southern Italy (see Mantovani et al., 1997b) through the mechanism tentatively sketched in fig. 4.

The seismic slip associated with intense decoupling earthquakes at the Adriatic-Balkan border causes a release of the Adriatic uparching, with a consequent downward motion of the Adriatic margin underlying the Apenninic belt (Mantovani et al., 1997b). The latter phenomenon may be accompanied by a collapse of the eastern side of the Southern Apennines, favoured by the seismic activation of normal faults, as occurred in the last strong Irpinia event of 1980 (e.g., Westaway and Jackson, 1987; Pingue et al., 1993; Giardini, 1993; Pan- tosti and Valensise, 1993). The migration of deformation triggered by the Hellenides-Dinarides decoupling earthquakes may also reach the Calabrian arc favouring the activation of normal and strike-slip faults. The above interpretational scheme may help to explain the very regular time correspondence between the most intense earthquakes in the Southern Dinarides and those in Southern Italy (fig. 5) pointed out by Mantovani and Albarello (1997). The values of the delay between the 'triggering' Dinaric events and the induced Apenninic earthquakes in fig. 5 suggest that the maximum intensity of the effects of the Adriatic unbending described above takes generally 1-2 years to reach the Italian zones.

The regularities in the seismicity patterns shown in figs. 3 and 5 seem to indicate that the phenomenon of «strain migration» exists and

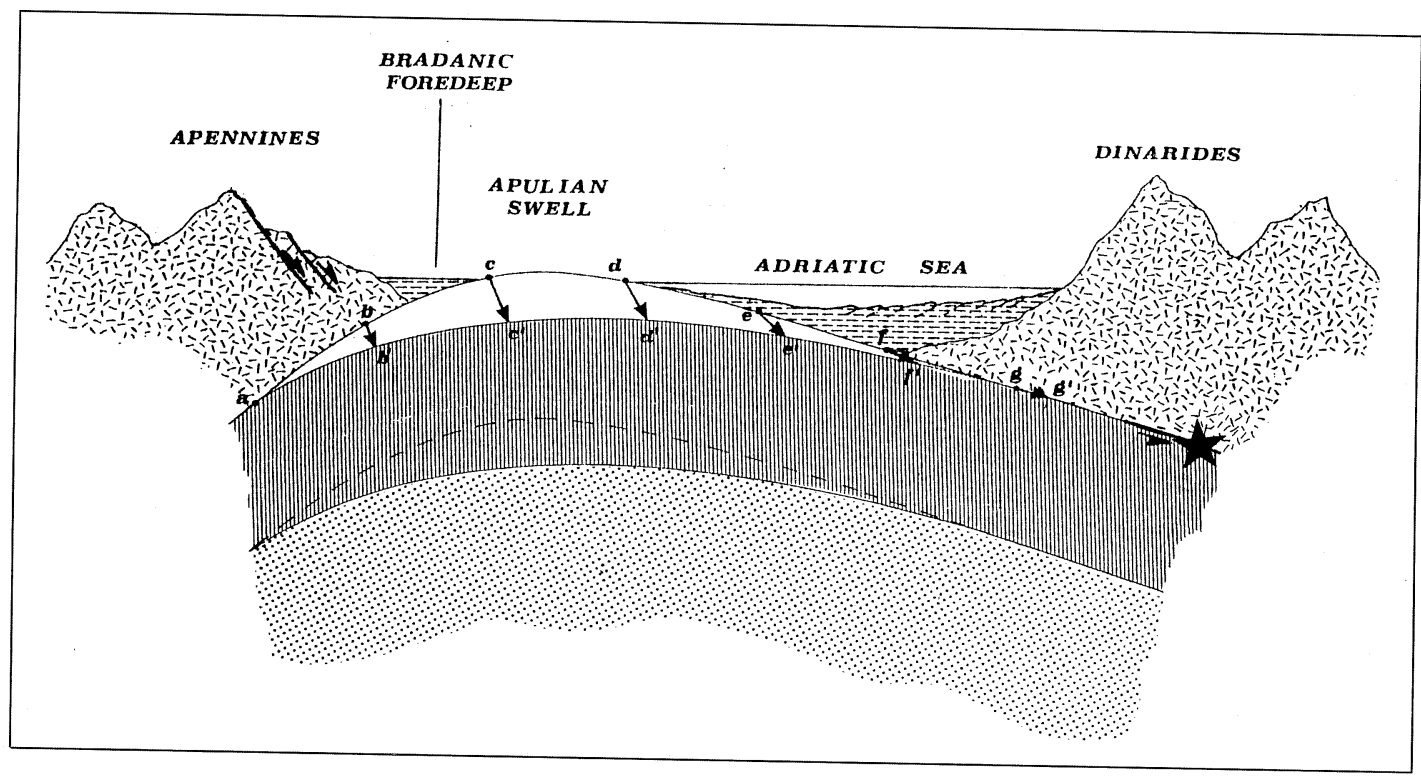

Fig. 4. Tentative sketch of the proposed «unbending» of the Southern Adriatic plate, in response to a decoupling earthquake (star) at the Adriatic-Dinarides compressional border. The transition from the initial (a, b, c, $\mathrm{d}, \mathrm{e}, \mathrm{f}, \mathrm{g})$ to the final $\left(b^{\prime}, c^{\prime}, d^{\prime}, e^{\prime}, f^{\prime}, g^{\prime}\right)$ flexural configurations is expected to develop by a velocity compatible with the relaxation time of the ductile layer (dotted) underlying the elastic-brittle Adriatic upper crust (dashed). It can be noted that this mechanism involves both horizontal and vertical displacements. When the migrating deformation reaches the westernmost zones underlying the Apennines, subvertical shear stresses may be induced inside the belt. This may cause the activation of normal faulting, as tentatively indicated in the figure by faults compatible with the mechanism of the last strong 1980 Irpinia earthquake. 

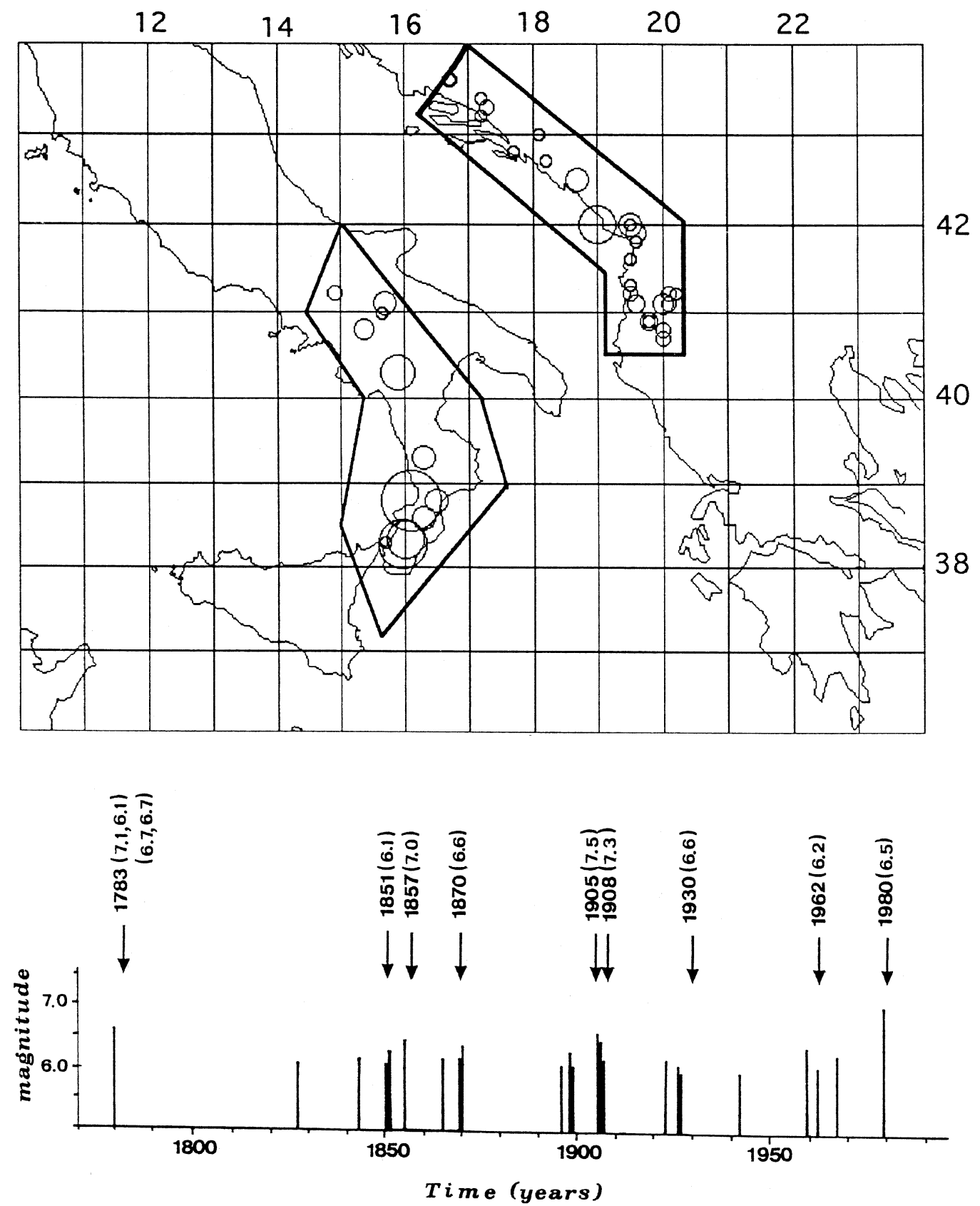

Fig. 5. Seismicity patterns in the Italian and Balkan zones surrounding the Southern Adriatic plate (after Mantovani and Albarello, 1997). The lower diagram reports the major seismic events $(M>6.0)$ in the AlbaniaMontenegro zone, while the arrows with dates and magnitudes show the strongest events in Southern Italy. Further comments in the text. 
produces appreciable effects in the peri-Adriatic seismic zones. These results, and eventual other indications which could derive from further investigations on the time-space distribution of earthquakes in the Central Mediterranean area, might encourage the use of the above phenomenon to recognize the periods of highest seismic hazard in some Italian seismic zones.

Further improvements in the knowledge of the tectonic setting and of the mechanisms of stress/strain propagation in the Central Mediterranean area may contribute to make this kind of approach more and more reliable. In this direction, we plan to make an extensive use of numerical modelling (Albarello et al., 1997) and analytical computations to try to reconstruct the perturbations of the stress/strain field caused by large shocks in each Central Mediterranean seismogenetic area, possibly tectonicall connected with the Italian active zones. This could allow estimation of strain accumulation in Italian seismic zones induced by each strong event in the Central Mediterranean area. This estimate, carried out for all major events in the known seismic history of the zones considered, may give an idea of the cumulative perturbation of seismic cycles in the Italian seismic sources which has been so far caused by the interactions with the surrounding active belts.

The problem posed by the unavoidable lack of information about the initial configuration of the system could be mitigated by using other kinds of data on the behaviour of seismic sources, provided, for instance, by paleoseismological and geomorphological studies. Further information about this problem might be obtained by using, through a trial and error procedure, part of seismic catalogues to formulate predictions and the remaining part of the catalogues to check the results obtained.

The results of the proposed approach could be used to plan other kinds of observations, such as the monitoring of minor seismicity and geodetic campaigns, with local dense networks etc., in the zones suspected of being in short-term alarm, in order to obtain more precise indications on the zones most close to failure.

\section{Conclusions and discussion}

At present, the chances of obtaining information on which Italian zones are most prone to next large earthquakes do not seem to be very good especially with the approaches so far proposed in the literature concerning Italy and other regions of the world.

All statistical analyses of the Italian seismic catalogues have clearly shown that the return times of strong shocks in the various seismogenetic zones do not present any significant regularity and that the associated probabilities may be estimated with considerable uncertainties. This leaves very little hope to recognize the zones where large events will occur next only on the basis of our present knowledge of Italian seismic history.

The identification of TIPs (Times of Increased earthquake Probability) by the pattern recognition technique in the Italian area seems to be characterized by relatively high probabilities of false alarms and by a scarce resolution on the location of the zones prone to the expected shock (Costa et al., 1996).

The recognition of possible «gaps» in the Italian area would require the presence of large-scale tectonic features, like a plate border, where most intense earthquakes in its different sectors are connected with a common tectonic mechanism, which, however, is not supported by any clear evidence. In fact, no significant systematic results have so far been obtained from attempts to apply this concept to the Mediterranean area.

More deterministic methods, like those based on the direct geodetic measurement of deformation rates, seem to have, at least theoretically, more chance to recognize the zones of highest strain accumulation rates and thus, presumably, of highest hazard. However, the availability of this information does not automatically imply that one can recognize the sites of the next disastrous earthquakes.

A promising approach, given the recognized plausibility of its underlying concepts, is the one based on the phenomenon of «strain migration». The chances of this approach to provide reliable indications in Italy are mostly conditioned by the use of correct information 
on the tectonic processes and the mechanisms of strain propagation in the Central Mediterranean area. This work argues that the reconstruction of the Central Mediterranean geodynamic setting and the related seismotectonic implications proposed by Mantovani et al. (1997a,b) might be used as a basis for the application of the strain migration method to the Italian region. The goodness of this choice can be evaluated by analyzing the validity of the arguments reported by the above authors.

Encouraging evidence in this sense is given by the observation of some significant regularities in the time patterns of seismicity in some peri-Adriatic zones, whose possible tectonic interpretations are fairly compatible with the geodynamic hypotheses proposed by Mantovani et al. (1997a,b). The above regularities suggest that the seismicity of Italy is strongly dependent on the «accelerations» of the Adriatic block, triggered by decoupling earthquakes along its borders. A monitoring of this phenomenon, by geodetic and geophysical observations could allow a more precise reconstruction of the migrating stress fronts and, consequently, of the expected effects in the Italian region. For this last purpose, any information on the location and previous strain accumulation of potential seismic faults, provided by paleoseismological, geomorphological and geodetic studies, would be extremely useful.

Some information in this sense could also be derived from computations of changes in Coulomb failure stress (Nostro et al., 1997) in the Italian region. However, the significance of the results obtained by these computations is strongly conditioned by the reliability of the rheological and tectonic modelling adopted.

\section{Acknowledgements}

This research has been supported by funds from the Gruppo Nazionale per la Difesa dai Terremoti (CNR) and the Ministry of University and Research (MURST).

\section{REFERENCES}

Albarello, D. and M. Bonafede (1990): Stress diffusion across laterally heterogeneous plates, Tectonophysics., 179, 121-130.

Albarello, D., E. Mantovani and M. Viti (1997): Finite element modelling of the recent-present deformation pattern in the Calabrian arc and surrounding regions, Ann. Geofis., 40, 833-848.

ANAGnOS, T. and A.S. KIREMIDJIAN (1984): Stochastic time-predictable model for earthquake occurrences, Bull. Seism. Soc. Am., 74, 2593-2611.

ANDERSON, D.L. (1975): Accelerated plate tectonics, Science, 167, 1077-1079.

ANDERSON, H. and J. JACKSON (1987): Active tectonics of the Adriatic region, Geophys. J. R. Astron. Soc., 91, 937-983.

BARKA, A.A. (1992): The North Anatolian fault zone, Ann. Tectonicae, 6, 164-195.

Biju-Duval, B., J. Dercourt and X. Le Pichon (1977): From the Tethys ocean to the Mediterranean sea: a plate tectonic model of the evolution of the Western Alpine system, in The Structural History of the Mediterranean Basin, edited by B. BuU-Duval and L. MONTADERT (Editions Technip, Paris), 143-164.

Boschi, E., P. GASPERINI and F. Mulargia (1995): Forecasting where larger crustal earthquakes are likely to occur in Italy in the near future, Bull. Seism. Soc. Am., 85, 1475-1482.

BOTT, M.P.H. and D.S. DEAN (1973): Stress diffusion from plate boundaries, Nature, 243, 339-341.

Bufe, C.G., P.W. Harsh and R.O. Burford (1977): Steady-state seismic slip-a precise recurrence model, Geophys. Res. Lett., 4, 91-94.

CAMASsi, R. and M. STUCCHI (1996): NT 4.1: un catalogo parametrico di terremoti italiani al di sopra della soglia del danno, Milano, Internet, http://www.emidius.itim. mi.cnr.it

Castellarin, A. and G.B. VAI (1986): Southalpine versus Po plain Apenninic arcs, in The Origin of Arcs, edited by F.C. WEZEL (Elsevier, Amsterdam), vol. 19, 253-280.

Costa, G., G.F. PANZA and I.M. Rotwain (1995): Stability of premonitory seismicity pattern and intermediateterm earthquake prediction in Central Italy, Pure Appl. Geophys., 145, 259-275.

Costa, G., I. Orozova-Stanishkova, G.F. Panza and I.M. RotwaIN (1996): Seismotectonic models and CN algorithm: the case of Italy, Pure Appl. Geophys., 147, 119-130.

DAvison, F.C. and C.H. Scholz (1985): Frequency-moment distribution of earthquakes in the Aleutian arc: a test of the characteristic earthquake model, Bull. Seism. Soc. Am., 75, 1349-1361.

DEWEY, J.W. (1976): Seismicity of Northern Anatolia, Bull. Seism. Soc. Am., 66 (3), 843-868.

Fedotov, S.A. (1965): Regularities of the distribution of strong earthquakes in Kamchatka, The Kurile Islands and Northeastern Japan (in Russian), Translation Inst. Fiz. Zemli, Akad.

FinetTI, I. and A. Del Ben (1986): Geophysical study of the Tyrrhenian opening, Boll. Geofis. Teor. Appl., 110, 75-156. 
GiARDINI, D. (1993): Teleseismic observation of the November 23 1980, Irpinia earthquake, Ann. Geofis. 36 (1), 17-25.

HABERMANN, R.E. and F. CREAMER (1994): Catalog errors and the $M 8$ earthquake prediction algorithm, Bull. Seism. Soc. Am., 84 (5), 1551-1559.

KaGAN, Y.Y. (1993): Statistics of characteristic earthquakes, Bull. Seism. Soc. Am., 83, 7-24.

KAGAN, Y.Y. and D.D. JACKSON (1991): Seismic gap hyphothesis: ten years after, J. Geophys. Res., 96, 21419 21431.

KAGAN, Y.Y. and D.D. JACKSON (1994): Long-term probabilistic forecasting of earthquakes, J. Geophys. Res., 99, 13685-13700.

KAGAN, Y.Y. and D.D. JACKSON (1995): New seismic gap hypothesis: five years after, J. Geophys. Res., 100 (3), 3943-3959.

KASAHARA, K. (1979): Migration of crustal deformation, Tectonophysics, 52, 329-341.

KeILIS-BoroK, V. I. and V.S. Kosobokov (1986): Time of increased probability for the great earthquakes of the world, Computational Seismology, 19, 48-57, Moscow, Nauka.

KeIlis-BoroK, V. I., I. V. Kuznetsov, G.F. PANZA, I.M. Rotwain and G. Costa (1990): On intermediate-term earthquake prediction in Central Italy, Pure Appl. Geophys., 134, (1), 79-92.

Kelleher, J.A., L.R. SyKes and J. Oliver (1973): Possible criteria for predicting earthquake locations and their applications to major plate boundaries of the Pacific and Caribbean, J. Geophys. Res., 78, 2547-2585.

KRUSE, S.E. and L.H. RoYdEN (1994): Bending and unbending of an elastic lithosphere: the Cenozoic history of the Apennine and Dinaride foredeep basins, Tectonics, 13, 278-302.

Mantovani, E. and D. Albarello (1997): Middle term precursors of strong earthquakes in Southern Italy, Phys. Earth Planet. Int., 101, 49-60.

Mantovani, E., D. Albarello, C. Tamburelli and D. BABBUCCI (1996): Evolution of the Tyrrhenian basin and surrounding regions as a result of the Africa-Eurasia convergence, J. Geodyn., 21, 35-72.

Mantovani, E., D. Albarello, C. Tamburelli, D. BabBUCCI and M. VITI (1997a): Plate convergence, crustal delimination, extrusion tectonics and minimization of shortening work as main controlling factors of the recent Mediterranean deformation pattern, Ann. Geofis., 40, 611-643.

Mantovani, E., D. Albarello, D. Babbucci and C. TAMBURELLI (1997b): Recent/Present tectonic processes in the Italian region and their relation with seismic and volcanic activity, Ann. Tectonicae (submitted).

MCCANN, W.R., S.P. Nishenko, L.R. SyKes and J. KRAUSE (1979): Seismic gaps and plate tectonics: seismic potential for major boundaries, Pure Appl. Geophys., 117, 1082-1147.

RCIER, J., D. SOREL, P. VERGELY and K. SimEAKIS (1989): Extensional tectonic regimes in the Aegean basins during the Cenozoic, Basin Res., 2, 49-71.

JGI, K. (1985): Earthquake Prediction (Acad. Press, Tokyo), pp. 355.

JLARGIA, F. and P. GASPERINI (1995): Evaluation of the applicability of the time- and slip-predictable earthquake recurrence models to Italian seismicity, Geophys. J. Int., 120, 453-473.

NISHENKO, S.P. (1985): Seismic potential for large and great inter-plate earthquakes along the Chilean and Southern Peruvian margins of South America: a quantitative reappraisal, J. Geophys. Res., 90, 3589-3615.

NisHENKO, S.P. (1991): Circum pacific seismic potential: 1989-1999, Pure Appl. Geophys., 135, 169-259.

NishenKo, S.P. and L.R. SYKES (1993): Comment on «Seismic gap hypothesis: ten years after» by Y.Y. KAGAN and D.D. JACKSON, J. Geophys. Res., 98, 99099916.

Nostro, C., M. Cocco and M.E. Belardinelli (1997): Static stress changes in extensional regimes: an application to Southern Apennines (Italy), Bull. Soc. Seism. Am., 87 (1), 234-248.

OMORI, F. (1909): Preliminary report on the Messina-Reggio earthquake of December 1908, in «Bulletin of the Imperial Earthquake Investigation Committee in Tokyo», vol. 3 (2).

Pantosti, D. and G. VAlensise (1993): Source geometry and long-term behavior of the 1980, Irpinia earthquake fault based on field geologic observations, Ann. Geofis., 36 (1), 41-49.

Pantosti, D., D.P. Schwartz and G. Valensise (1993): Paleoseismology along the 1980 surface rupture of the Irpinia fault: implications for earthquake recurrence in Southern Apennines, Italy, J. Geophys. Res., 98, 65616577.

PAPAZACHOS, B.C. (1989): A time-predictable model for earthquake generation in Greece, Bull. Seism. Soc. Am., 79, 77-84.

Patacca, E., R. SARTori and P. SCANDOne (1990): Tyrrhenian basin and Apenninic arcs: kinematic relations since Late Tortonian times, Mem. Soc. Geol. It., 45, 425-451.

Pavlides, S.B., N.C. Zouros, A.A. Chatzipetros, D.S. Kostopoulos and D.M. Mountrakis (1995): The 13 May 1995 Western Macedonia, Greece (Kozani Grevena) earthquake; preliminary results, Terra Nova, 7, 544-549.

Pingue, F., G. De Natale and F. Briole (1993): Modeling of the 1980 Irpinia earthquake source: constraints from geodetic data, Ann. Geofis., 36 (1), 27-40.

Purcaru, G. and H. Berckhemer (1982): Regularity patterns and zones of seismic potential for future large earthquakes in the Mediterranean region, Tectonophysics, 85, 1-30.

ReHault, J.P., E. Moussat and A. FABbri (1987): Structural evolution of the Tyrrhenian back-arc basin, Mar. Geol., 74, 123-150.

RIBARICH, V. (1982): Seismicity of Slovenia, Catalog of Earthquake (792-1981), Bull. Seism. S.R. Slovenia, Ljubljana.

Richardson, R.M., A.S. Freed and T. WAllace (1993): Is the seismic gap hypothesis testable? Eos, Trans. $A G U, 74$ (43), Fall meeting suppl., 425.

Roure, F., P. Choukroune and R. Polino (1996): Deep seismic reflection data and new insights on the bulk geometry of mountain ranges, C. R. Acad. Sci. Paris, t. 332, ser. IIa, 359-435.

Royden, L. (1988): Late Cenozoic tectonics of the Pan- 
nonian basin system, in The Pannonian Basin: a Study in Basin Evolution, edited by L.H. ROYDEN and F. HORVATH, AAPG Hemoir, 45, 27-48.

Royden, L., E. Patacca and P. Scandone (1987): Segmentation and configuration of subducted lithosphere in Italy: an important control on thrust-belt and foredeep-basin evolution, Geology, 15, 714-717.

SCANDONE, P. (1992): Il modello sismotettonico italiano, in Convegno Annuale GNDT, CNR, Milano, May 25-26.

SCHWARTZ, D.P. and K.J. COPPERSMITH (1984): Fault behavior and characteristic earthquake: examples from Wasatch and San Andreas fault zone, J. Geophys. Res., 89, 5681-5698.

Shebalin, N.B., B. KarniK and D. HadzIEwKI (Editors)(1974): UNDP/UNESCO Survey of the Balkan region, Catalogue of Earthquakes (part. I, 1901-1970), UNESCO, Paris.

ShIMAZAKI, K. and T. NAKATA (1980): Time predictable recurrence models for large earthquakes, Geophys. Res. Lett., 7, 279-282.

Slejko, D., G.B. Carulli, R. Nicolich, A. Rebez, A. Zanferrari, A. Cavallin, C. Doglioni, F. CarRaro, I. Castaldini, V. Iliceto, E. Semenza and C. ZANOLLA (1989): Seismotectonics of the Eastern Southern Alps: a review, Boll. Geofis Teor. Appl., 122, 109-136.

SteIn, R.S., A.A. BARKA and J.H. DieTERICH (1997): Progressive failure on the North Anatolian fault since 1939 by earthquake stress triggering, Geophys. J. Int., 128, 594-604.
STIROS, S. (1995): Unexpected shock rocks an «aseismic» area, Eos, 12, 513-519.

SYKES, L.R. (1971): Aftershock zones of great earthquakes, seismicity gaps and earthquake prediction for Alaska and the Aleutians, J. Geophys. Res., 76, 80218041.

SyKES, L.R. and R.C. QUITTMEYER (1981): Repeat time of great earthquakes along simple plate boundaries, in D.W. SIMPSON and P.G. RICHARDS Earthquake Prediction, an International Review, edited by Maurice Ewing Series, 4, 297-332.

VALENSISE, G. and E. GuIDOBoni (1995): Verso nuove strategie di ricerca: zone sismogenetiche silenti o silenzio delle fonti? in Catalogo dei Forti Terremoti in Italia dal 461 a.C. al 1980, Istituto Nazionale di Geofisica-SGA, 112-127.

Viti, M., D. Albarello and E. Mantovani (1997): Rheological profiles in the Central-Eastern Mediterranean, Ann. Geofis., 40, 849-864.

WAKEFIELD, J. and D. PENDICK (1995): Earthquake reality check, Earth Beat, August 1995, 20-21.

WARD, S.N. (1994): A multidisciplinary approach to seismic hazard in Southern California, Bull. Seism. Soc. Am., 84, 1293-1309.

WestawAY, R. and J. JACKSON (1987): The earthquake of 1980 November 23 in Campania Basilicata (Southern Italy), Geophys. J. R. Astron. Soc., 90, 375-443.

WGCEP (Working Group on California Earthquake Prediction) (1995): Seismic hazard in Southern California: probable earthquake, 1994 to 2024, Bull. Seism. Soc. Am., 85 (2), 379-439. 